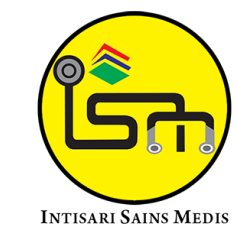

Published by Intisari Sains Medis

\title{
The comparison of Body Mass Index (BMI) and Muscle Mass Index (MMI) as a mortality predictor in patients with malignant jaundice at Dr. Sardjito General Hospital, Yogyakarta, Indonesia
}

\author{
Briand Iggreinus Pollah ${ }^{1 *}$, Adeodatus Yuda Handaya ${ }^{2}$, Agus Barmawi ${ }^{2}$
}

${ }^{1}$ Trainee of Digestive Surgery, Dr. Sardjito General Hospital, Faculty of Medicine, Public Health, and Nursing, Universitas Gadjah Mada, Yogyakarta, Indonesia;

${ }^{2}$ Digestive Surgery, Surgery Department, Dr. Sardjito General Hospital, Faculty of Medicine, Public Health, and Nursing, Universitas Gadjah Mada, Yogyakarta, Indonesia;

*Corresponding author:

Briand Iggreinus Pollah;

Trainee of Digestive Surgery, Dr. Sardjito General Hospital, Faculty of Medicine, Public Health, and Nursing, Universitas Gadjah Mada, Yogyakarta, Indonesia;

briandiggrey@gmail.com

Received: 2021-07-04

Accepted: 2021-08-19

Published: 2021-08-31

\section{ABSTRACT}

Background: Jaundice is found to be a clinical manifestation of malignancy. Around $70 \%$ of all jaundice cases are caused by malignancy. Another complication of malignancy is decreasing the Muscle Mass Index (MMI), also called sarcopenia. MMI in malignant jaundice increases the mortality rate. Body Mass Index (BMI) is describing the nutritional status of a person. Due to malnutrition, morbidity and mortality increase. This study aims to compare the MMI and BMI in patients with malignant jaundice to predict the outcome of mortality.

Methods: This study is a retrospective cross sectional non-experimental epidemiologic analysis. Samples were taken from medical reports at Sardjito Hospital from April 2019 - March 2020. A CT scan calculated MMI at the third lumbar vertebrae. BMI was evaluated by

body weight $(\mathrm{kg})$ divided by height $(\mathrm{m})$ square $\left(\mathrm{kg} / \mathrm{m}^{2}\right)$. Data were analyzed using SPSS version 20 for Windows. Results: Most of respondents were males (55.0\%), following by age $\geq 50(62.5 \%)$, stage $3(62.5 \%)$, ASA 2 (92.5\%), albumin $<3.5 \mathrm{~g} / \mathrm{dL}(82.5 \%)$, CA19-9 $\geq$ $37 \mathrm{U} / \mathrm{ml}(57.5 \%)$, CEA $<5 \mathrm{ng} / \mathrm{ml}(62.5 \%)$, and total bilirubin $\geq 1.5 \mathrm{mg} / \mathrm{dL}(90.0 \%)$, normal BMI $(62.5 \%)$, survive $(77.5 \%)$, and low MMI (72.5\%). There was no significant relationship between MMI (0R: $5.71 ; 95 \% \mathrm{Cl}$ : $0.60-134.12$ ) and BMI (OR: $0.15 ; 95 \% \mathrm{Cl}: 0.02-1.34)$ to the mortality risk ( $p>0.05$ ).

Conclusion: MMI had a higher incidence of mortality compared to BMI in malignant jaundice. However, there was no significant relationship between MMI and BMI to predict mortality.

Keywords: BMI, MMI, Malignant Jaundice, Mortality.

Cite This Article: Pollah, B.I., Handaya, A.Y., Barmawi, A. 2021. The comparison of Body Mass Index (BMI) and Muscle Mass Index (MMI) as a mortality predictor in patients with malignant jaundice at Dr. Sardjito General Hospital, Yogyakarta, Indonesia. Intisari Sains Medis 12(2): 695-699. D0I: 10.15562/ism.v12i2.1083

\section{INTRODUCTION}

One complication of malignancy is decreased Muscle Mass Index (MMI), also known as sarcopenia. ${ }^{1}$ Sarcopenia is experienced as a decrease in muscle function as well as muscle mass itself. ${ }^{1}$ The signs of sarcopenia are fatigue, defined as decreased activity, mobility, slow walk, and immunity. As it is a topic that emerged recently, many doctors and researchers are not yet familiar with sarcopenia and its effects on the treatment of cancer patients. ${ }^{1}$ The patient's nutritional status can be reflected by calculating the Body Mass Index (BMI). In malignancy, the BMI of a patient may experience a rapid decrease and requires good nutritional regulation.
Malnutrition is defined by a BMI of $<18.5$ and $>22.9 .^{2}$ Malignancy may cause jaundice and supports a worse prognosis, similar to pancreatic cancer, cholangiocarcinoma, gallbladder cancer, tumour of the ampulla vateri and more. On presentation, cancer commonly underwent distant metastasis. ${ }^{2}$ Jaundice can be clinically detected when the total bilirubin level $>2.5 .^{3,4}$ MMI is easily detected by an abdominal CTScan which is routinely carried out in patients preoperatively; therefore, the MMI is a significant predictor of the patient's outcome. ${ }^{5}$ Few reports state that the factors enhancing jaundice are age, gender, sepsis, bilirubin level, Ca 19-9, albumin levels, drainage procedure, and other comorbidities. ${ }^{6-13}$
There is no known evidence comparing MMI and BMI in malignant jaundice to predict the mortality rate in Sardjito Hospital Yogyakarta. Based on those mentioned above, this study aims to evaluate the comparison of BMI and MMI as a mortality predictor in patients with malignant jaundice at Dr. Sardjito General Hospital, Yogyakarta, Indonesia.

\section{METHODS}

This research was designed as a retrospective cohort where samples were collected retrospectively from medical records in Dr. Sardjito General Hospital from April 2019 through March 2020. All patients diagnosed with biliary duct cancer and were admitted to the surgery 
Table 1. Demographic of Clinical characteristics of samples with Jaundice Malignancies.

\begin{tabular}{|c|c|c|}
\hline Variable & $\mathrm{N}=40$ & $\%$ \\
\hline \multicolumn{3}{|l|}{ Gender } \\
\hline Male & 22 & 55.0 \\
\hline Female & 18 & 45.0 \\
\hline \multicolumn{3}{|l|}{ Age (Years) } \\
\hline$\geq 50$ & 25 & 62.5 \\
\hline$<50$ & 15 & 37.5 \\
\hline \multicolumn{3}{|l|}{ Stage } \\
\hline 4 & 15 & 37.5 \\
\hline 3 & 25 & 62.5 \\
\hline 2 & 0 & 0 \\
\hline 1 & 0 & 0 \\
\hline \multicolumn{3}{|l|}{ ASA Criteria } \\
\hline 1 & 0 & 0 \\
\hline 2 & 37 & 92.5 \\
\hline 3 & 3 & 7.5 \\
\hline \multicolumn{3}{|l|}{ Albumin (g/dL) } \\
\hline$<3.5$ & 33 & 82.5 \\
\hline$\geq 3.5$ & 7 & 17.5 \\
\hline \multicolumn{3}{|l|}{ CA19-9 (U/ml) } \\
\hline$\geq 37$ & 23 & 57.5 \\
\hline$<37$ & 17 & 42.5 \\
\hline \multicolumn{3}{|l|}{ CEA (ng/ml) } \\
\hline$\geq 5$ & 15 & 37.5 \\
\hline$<5$ & 25 & 62.5 \\
\hline \multicolumn{3}{|l|}{ Total Bilirubin (mg/dL) } \\
\hline$\geq 1.5$ & 36 & 90.0 \\
\hline$<1.5$ & 4 & 10.0 \\
\hline \multicolumn{3}{|l|}{ Body Mass Index (BMI) (kg/m²) } \\
\hline Malnourished & 15 & 37.5 \\
\hline Normal & 25 & 62.5 \\
\hline \multicolumn{3}{|l|}{ Mortality } \\
\hline Death & 9 & 22.5 \\
\hline Survive & 31 & 77.5 \\
\hline \multicolumn{3}{|l|}{ Muscle Mass Index (MMI) $\left(\mathrm{cm}^{2} / \mathrm{m}^{2}\right)$} \\
\hline Low & 29 & 72.5 \\
\hline Normal & 11 & 27.5 \\
\hline
\end{tabular}

ward were included in this research. The research was registered in the ethical committee of the Medical, Public Health and Nursing Faculty Universitas Gadjah Mada in 2020. The inclusion criteria were jaundice, weight loss, increased tumour markers with a suspect of biliary duct cancer. An abdominal CT-Scan with contrast was carried out. To calculate MMI in every patient, the total surface area of the muscles at the third lumbar vertebrae inferiorly were measured manually. The muscles included were psoas, erector spinae, quadratus lumborum, transversus abdominis, obliques externus et internus, and rectus abdominis. All muscles were identified by an HU of 29 to +150 . The cross-section of the muscles $\left(\mathrm{cm}^{2}\right)$ in the lumbar region were measured manually on the CT printout. Muscle area was normalized for height $\left(\mathrm{m}^{2}\right)$ and was reported as L3 Muscle index (L3 MI) $\left(\mathrm{cm}^{2} /\right.$ $\mathrm{m}^{2}$ ). The cut off to diagnose low MMI was the same as stated in the previous study, such as $36.0 \mathrm{~cm}^{2} / \mathrm{m}^{2}$ for males and 29.0 $\mathrm{cm}^{2} / \mathrm{m}^{2}$ for female samples. All individuals with scores lower than the cut off were diagnosed with sarcopenia. ${ }^{5}$

BMI was calculated by dividing weight (kg) with height $(\mathrm{m})$ in a square. The BMI definition of underweight was $<18.5$ $\mathrm{kg} / \mathrm{m}^{2}$ and $>22.9 \mathrm{~kg} / \mathrm{m}^{2}$ was described as overweight. Both underweight and overweight was stated malnourished. The relevant variables were transcribed to SPSS version 20 for Windows. Univariate analysis was used to describe the patient population where the continuous variable was shortened into the average; the categorical variables were stated in a table in percentage form. Bivariate analysis was done using chi-square to analyze the categorical variables in categories. After the chi-square analysis, the predictive values for mortality could be shown by the odds ratio of the exposed group. Survival analysis was evaluated by Kaplan Meier to compare the survival and mortality rates of the sarcopenia group compared to the non-sarcopenia group. The multivariate analysis was used if there were more than one significant variable. The result was stated significant if it was at $5 \%$.

\section{RESULTS}

Of 40 patients who participated in the research $55 \%$ were male and $45 \%$ female, the majority of patients were over 50 years old (60\%). The concentration of Albumin serum $<3,4 \mathrm{mg} / \mathrm{dL}$ was $80.0 \%$, the majority of tumor marker Ca 19-9 > 37 U/mL was $65.0 \%$, followed by tumor marker CEA < $5 \mathrm{mg} / \mathrm{ml}(62.5 \%)$, total bilirubin $>1,5 \mathrm{mg} /$ $\mathrm{dl}$ was $90 \%$, the majority of normal BMI $(18,5-22,9)$ was $(62,5 \%)$, the majority of L3 MMI (L<36 dan P <29) was $(77,5 \%)$, the majority of non-metastasis stage (stage 3) was $(62,5 \%)$, a majority of patients with ASA 2 was $(92,5 \%)$, every patient underwent surgery and the majority of patients survived $(77,5 \%)$, percentage of patients who died was $22,5 \%$. The percentage of sarcopenia patients was (72,5\%) (Table 1).

To determine the thickness of muscle mass, an abdominal CT scan at an axial image of the vertebra lumbar 3 , some muscles that were objected to in determining mass muscle thickness included the rectus abdominis muscle and psoas, oblique externus and internus muscle and erector spine muscle. In Figure 1 , the difference between normal muscle mass and abnormal muscle mass is shown.

The result of statistical analysis between low MMI and mortality shows no significant difference $(\mathrm{p}=0.132)$. Still, in patients with low MMI, the mortality rate increased by 5.71 times higher than patients with normal MMI (Table 2). The analysis was based on BMI analysis in 8 patients with normal BMI who died and 
1 patient with malnourished BMI. There was no significant correlation between BMI and mortality ( $\mathrm{p}=0.117$ ) (Table 2).

Twenty-nine patients had low MMI, 9 patients died, 15 patients had malnourished BMI, and 25 patients had normal BMI. In addition, statistical analysis between MMI and BMI did not show significant results $(\mathrm{p}=0.273)$ (Table 3).

In the Kaplan Meier analysis, a diagram shows all non-sarcopenia patients survived. In contrast, the survival rate of sarcopenia patients at 20 days of care was $50.0 \%$ with a $\mathrm{p}$ log-rank of 0.081 ( $\mathrm{p}>0.05)$, so that there was no statistically significant difference (Figure 2).

\section{DISCUSSION}

Muscle mass loss in malignancy patients is a form of complication that may affect the patient's outcome. An abdominal CT scan detects muscle mass loss in Lumbal 3. Every malignancy patient undergoes CT scan examination to determine resectability and spread of cancer. Prospective research in 95 cases of biliary tract malignancies states that low MMI is an independent risk factor for complications after surgery. ${ }^{14}$ In prospective control research of 75 cases of biliary tract malignancies, low MMI is a risk of bad quality of life in patients with biliary tract malignancies, such as inflammations, low immunity, from neutrophil to lymphocyte ratio (NLR), are also independent predictors for quality of life. ${ }^{15}$ A previous study found that biliary tract malignancies with high NLR and low MMI has shown unfavourable results. ${ }^{15}$

Some mechanisms explain that jaundice has adverse effects, like damaging
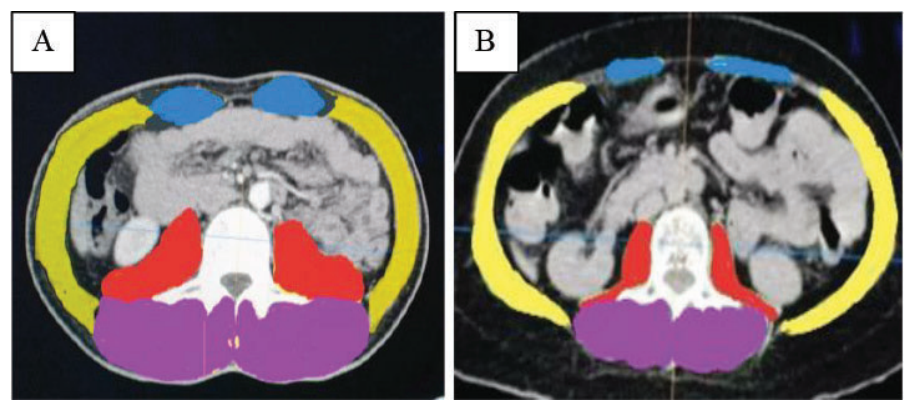

$=$ Rectus Abdominis muscle = internal and external obliquus muscle $=$ Psoas Muscle

Figure 1. (A) Normal muscle mass index and (B) Sarcopenia.

cellular immunity, which follows tumour growth and progressivity in malignancies if management is not done correctly. Obstructions in biliary tracts will decrease the viability of digestive tracts absorption of vitamins and fat, including vitamin $\mathrm{K}$ that may result in coagulopathy and increase the risk of bleeding throughout the surgery. Bacterial and germ translocation from mucus in the digestive tract can happen in jaundice patients and cause further serious complications such as sepsis. ${ }^{16}$ Jaundice can be caused by direct infiltration from a tumour, lymph node involvement, and an intraluminal tumour. ${ }^{17}$ In this research, 9 patients with low MMI died.

However, statistical analysis results of MMI compared to mortality did not prove significant with a score of $\mathrm{p}=0,132$, but from OR 5.71 times more causing mortality. Low MMI has a risk of increased mortality according to a previous study. ${ }^{18}$ A research in 75 cases of biliary tract malignancies mentioned that low MMI is a risk of bad quality of life in patients with biliary tract malignancies, such as inflammations and low immunity, from neutrophil to lymphocyte ratio (NLR), are also an independent predictor for quality of life. A previous study found that malignancy in the biliary tract with high NLR and low MMI has shown

Table 2. Analysis results predicting MMI and BMI compared to mortality

\begin{tabular}{|c|c|c|c|c|c|c|}
\hline \multirow{3}{*}{ Variable } & \multicolumn{4}{|c|}{ Mortality Groups $(n=40)$} & \multirow{3}{*}{ OR } & \multirow{3}{*}{$\mathbf{p}$} \\
\hline & \multicolumn{2}{|c|}{ Death $(n=9)$} & \multicolumn{2}{|c|}{ Survival $(n=31)$} & & \\
\hline & n & $\%$ & $\mathbf{n}$ & $\%$ & & \\
\hline \multicolumn{7}{|l|}{ MMI } \\
\hline Low & 9 & 100.00 & 20 & 64.50 & $5.71(0.60-134.12)$ & 0.132 \\
\hline Normal & 0 & 0 & 11 & 35.50 & & \\
\hline \multicolumn{7}{|l|}{ BMI } \\
\hline Malnourished & 1 & 11.10 & 14 & 45.20 & $0.15(0.02-1.34)$ & 0.117 \\
\hline Normal & 8 & 88.90 & 17 & 54.80 & & \\
\hline
\end{tabular}

MMI: Muscle Mass Index; BMI: Body Mass Index; OR: Odds-Ratio; ${ }^{\star}$ Chi-Square: Statistically significant if p-value less than 0.05

Table 3. The relationship between MMI compared to BMI groups

\begin{tabular}{|c|c|c|c|c|c|c|}
\hline \multirow{3}{*}{ Variable } & \multicolumn{4}{|c|}{ BMI Groups $(n=40)$} & \multirow{3}{*}{ OR } & \multirow{3}{*}{$\mathbf{p}$} \\
\hline & \multicolumn{2}{|c|}{ Malnourished $(n=15)$} & \multicolumn{2}{|c|}{ Normal $(n=25)$} & & \\
\hline & $\mathbf{n}$ & $\%$ & $\mathbf{n}$ & $\%$ & & \\
\hline \multicolumn{7}{|l|}{ MMI } \\
\hline Low & 9 & 60.00 & 20 & 80.00 & $0.375(0.09-1.56)$ & 0.273 \\
\hline Normal & 6 & 40.00 & 5 & 20.00 & & \\
\hline
\end{tabular}

MMI: Muscle Mass Index; BMI: Body Mass Index; OR: Odds-Ratio; ${ }^{\star}$ Chi-Square: Statistically significant if p-value less than 0.05. 


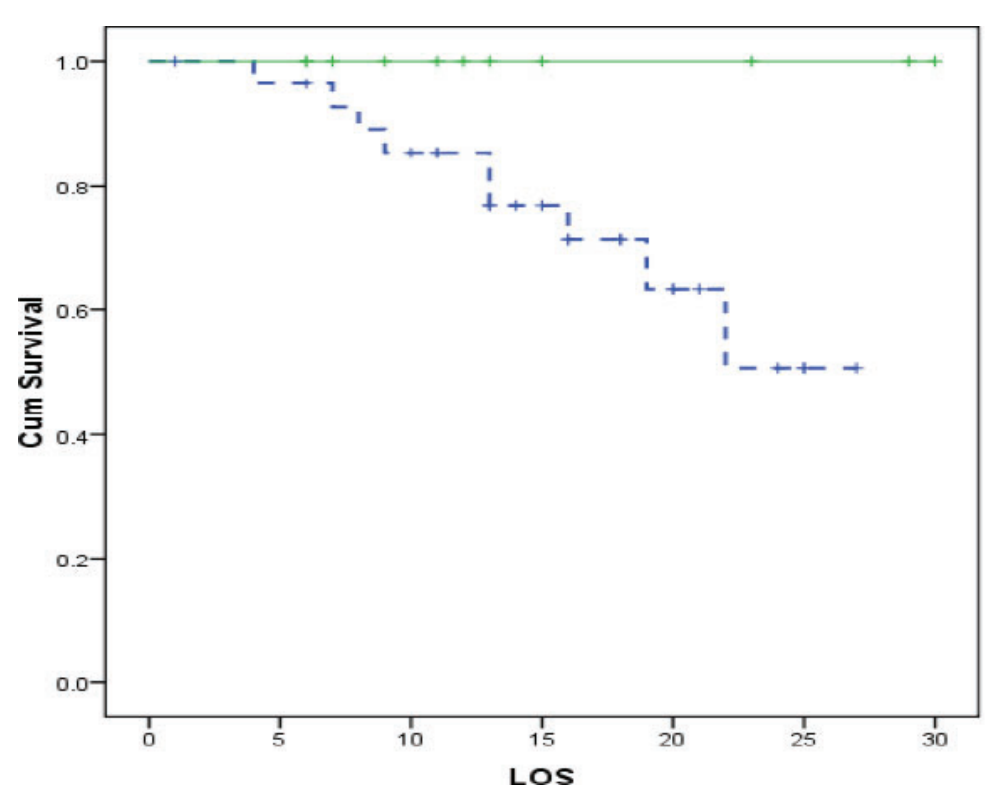

Figure 2. Kaplan Meier graphic of sarcopenia versus death.

unfavourable results. ${ }^{15}$ According to the Global Burden of Disease, only 10\% of patients with biliary tract malignancies can undergo curative resection that will increase the mortality rate in patients with low MMI. ${ }^{19}$ Body Mass Index reflects nutrition and catabolism. In this research, 9 malnourished patients were involved, one patient (11.1\%) was malnourished, and $8(88.9 \%)$ with normal BMI died. The number of patients who died with normal BMI was higher than those with malnourished BMI. Mortality increased in malnourished patients.

Patients with malignancy have a higher risk of malnourished cases..$^{20}$ This research showed different results in which more patients with normal BMI died. This is caused by faster tumour growth and spread, resulting in worse complications. Nonetheless, in this research, no significant relationship was found between BMI and mortality $(p=0.117)$. A non-significant relationship was also found between MMI and BMI ( $\mathrm{p}=0.273)$. Malignancies with low BMI reflected nutrition and catabolism status. Low BMI related to low MMI. ${ }^{14}$ The biggest mortality was found in patients with low MMI. In patients with malignant jaundice, evaluating the prognosis by MMI is more accurate besides novel biomarkers. $^{21}$

\section{CONCLUSION} regarding the manuscript.

\section{FUNDING} resources. d final approval of the version to be published, and agreeing to be accountable for all study aspects.

\section{REFERENCES}

1. Chindapasirt J. Sarcopenia in Cancer Patients. Asian Pac J Cancer Prev. 2015;16(18):8075-8077.

2. Oto BT, Fauzi A, Syam AF, Simadibrata M, Abdullah M, Makmun D, et al. Identification and stenting malignant obstruction jaundice: determining the success rate of ERCP. Indonesia J Gastroenterol Hepatol Dig Endosc. 2012;13(1):19-22.

3. Garcea G, Ngu W, Neal CP, Dennison AR, Berry DP. Bilirubin levels predict malignancy in patients with obstructive jaundice. HPB (Oxford). 2011;13(6):426-430.

4. Ohashi K, Ishikawa T, Hoshi A, Suzuki M, Mitobe Y, Yamada E, et al. Relationship Between Sarcopenia and Both Physical Activity and Lifestyle in Patients With Chronic Liver Disease. J Clin Med Res. 2018;10(12):920-927.

MMI in the statistical analysis does not provide meaningful results, but the incidence rate is relatively high. BMI statistical analysis did not provide significant results. There was no significant relationship between MMI and BMI on mortality in patients with Jaundice malignancy. Patients with low MMI have a high risk of mortality. MMI can be used as an indicator predicting mortality.

\section{ETHICS CONSIDERATION}

Ethics approval has been obtained from the Ethics Committee of Clinical Research, Faculty of Medicine, Universitas Gadjah Mada, Dr.Sardjito General Hospital, Yogyakarta, Indonesia, based on COPE protocol prior to the study conducted.

\section{CONFLICT OF INTEREST}

The authors declare no conflict of interest

This study was self-funded by authors without the involvement of grants, scholarships, or any other funding
5. Huang DD, Wang SL, Zhuang CL, Zheng BS, $\mathrm{Lu}$ JX, Chen FF, et al. Sarcopenia, as defined by low muscle mass, strength and physical performance, predicts complications after surgery for colorectal cancer. Colorectal Dis. 2015;17(11):O256-64.

6. Moghimi M, Marashi SA, Salehian MT, Sheikhvatan M. Obstructive jaundice in Iran: factors affecting early outcome. Hepatobiliary Pancreat Dis Int. 2008;7(5):515-519.

7. Yusuf F, Innayah MR, Maghfirah D, Azzaki, Riswan M. Obstructive jaundice as manifestation of relapsing Hodgkin's Lymphoma: the success of chemotherapy (case report). Bali Medical Journal. 2020;9(1):115120.

8. Qiu YD, Bai JL, Xu FG, Ding YT. Effect of preoperative biliary drainage on malignant obstructive jaundice: a meta-analysis. World J Gastroenterol. 2011;17(3):391-396.

9. Ballehaninna UK, Chamberlain RS. The clinical utility of serum CA 19-9 in the diagnosis, prognosis and management of pancreatic adenocarcinoma: An evidence based appraisal. J Gastrointest Oncol. 2012;3(2):105-119.

10. Myatra S, Divatia JV, Jibhkate B, Barreto GS, Shrikhande SV. Preoperative assessment and optimization in periampullary and pancreatic cancer. Indian J Cancer. 2011;48(1):86-93.

11. Sut M, Kennedy R, McNamee J, Collins A, Clements B. Long-term results of percutaneous transhepatic cholangiographic drainage for palliation of malignant biliary obstruction. J Palliat Med. 2010;13(11):1311-1313.

12. Fernández-Ruiz M, Guerra-Vales JM, ColinaRuizdelgado F. Comorbidity negatively influences prognosis in patients with extrahepatic cholangiocarcinoma. World J Gastroenterol. 2009;15(42):5279-5286. 
13. Jeurnink SM, Steyerberg EW, Vleggaar FP, van Eijck $\mathrm{CH}$, van Hooft JE, Schwartz MP, et al. Predictors of survival in patients with malignant gastric outlet obstruction: a patient-oriented decision approach for palliative treatment. Dig Liver Dis. 2011;43(7):548-52.

14. Zhou G, Bao H, Zeng Q, Hu W, Zhang Q. Sarcopenia as a prognostic factor in hepatolithiasis-associated intrahepatic cholangiocarcinoma patients following hepatectomy: a retrospective study. Int J Clin Exp Med. 2015;8(10):18245-18254.

15. Chen LK, Liu LK, Woo J, Assantachai P, Auyeung TW, Bahyah KS, et al. Sarcopenia in Asia: consensus report of the Asian Working Group for Sarcopenia. J Am Med Dir Assoc. 2014;15(2):95-101.
16. Boulay BR, Birg A. Malignant biliary obstruction: From palliation to treatment. World J Gastrointest Oncol. 2016;8(6):498-508.

17. Tran TB, Norton JA, Ethun CG, Pawlik TM, Buettner S, Schmidt C, et al. Gallbladder Cancer Presenting with Jaundice: Uniformly Fatal or Still Potentially Curable? J Gastrointest Surg. 2017;21(8):1245-1253.

18. Brown JC, Harhay MO, Harhay MN. Sarcopenia and mortality among a population-based sample of community-dwelling older adults. J Cachexia Sarcopenia Muscle. 2016;7(3):290298.

19. Yoon SB, Choi MH, Song M, Lee JH, Lee IS, Lee MA, Hong TH, Jung ES, Choi MG. Impact of preoperative body compositions on survival following resection of biliary tract cancer. J
Cachexia Sarcopenia Muscle. 2019;10(4):794802.

20. Arends J, Baracos V, Bertz H, Bozzetti F, Calder PC, Deutz NEP, et al. ESPEN expert group recommendations for action against cancer-related malnutrition. Clin Nutr. 2017;36(5):1187-1196.

21. Takenami T, Maeda S, Karasawa H, Suzuki T, Furukawa T, Morikawa T, et al. Novel biomarkers distinguishing pancreatic head Cancer from distal cholangiocarcinoma based on proteomic analysis. BMC Cancer. 2019;19(1):318.

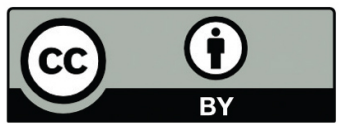

This work is licensed under a Creative Commons Attribution 